\title{
Reliability of Strain Estimation on Triangular Network and A Case Study; Deformation of Korea due to 2011 Tohoku Earthquake observed by GPS
}

\author{
Sung-Ho Na ${ }^{1}$, Tae Woong Chung ${ }^{2 *}$, Byung-Kyu Choi ${ }^{3}$, and Sung-Moon Yoo $^{3}$ \\ ${ }^{1}$ Korea Space Geodetic Observation Center, Sejong 339-821, Korea (on leave from Ajou University) \\ ${ }^{2}$ Sejong University, Seoul 143-747, Korea \\ ${ }^{3}$ Korea Astronomy and Space Science Institute, Daejeon 305-348, Korea
}

\section{삼각망에서 변형률산출의 신뢰도와 적용례; GPS로 관측된 2011 토호쿠지진에 의한 한반도 변형}

\author{
나성호 $^{1} \cdot$ 정태웅 ${ }^{2 *} \cdot$ 최병규 $^{3} \cdot$ 유성문 $^{3}$ \\ 1 한국우주측지관측센터 (아주대 파견) \\ ${ }^{2}$ 세종대학교 에너지자원공학과 \\ 3한국천문연구원
}

\begin{abstract}
A stable procedure is presented to attain most probable and unbiased estimate of principal strain, rotation, and dilatation for 2-dimensional geodetic data on triangular network. The proper network size should be chosen carefully, because the errors of these estimates of strain tensor and other associated observables grow inversely proportional to the area of station triangle. As a case study, the deformation observables for the GPS-monitored co-seismic displacement in Korea due to the 2011 Tohoku-Oki earthquake were attained accordingly.
\end{abstract}

Keywords: Deformation, Unbiased Estimate, Network Size, Stable Procedure, GPS, 2011 Tohoku Earthquake

요 약: 삼각망에서 얻은 2차원 변위자료로부터 주축변형, 회전, 팽창등을 산출하는 안정된 계산순서를 제시하였으며, 이 들 추산치의 오차가 삼각망의 면적간에 반비례하므로 자료망의 크기를 택함에 유의하여야함을 지적하였다. 이 순서를, 2011년 토호쿠지진에 의해 발생한 한반도지역의 변위의 GPS관측자료에 적용하여 안정된 추산치들을 얻었다.

주요어: 변형, 최적추정치, 자료망의 크기, 안정된 계산순서, GPS, 2011년 토호쿠지진

\section{Introduction}

Most probable and unbiased estimation by imposing the condition of least sum of square error was first developed by Gauss. This concept of least square technique has been widely used in branches of science and engineering dealing with precise measurements. One of the disciplines, which demand frequent application of 'least square estimation' or

2013년 5월 27일 접수; 2013년 10월 25일 수정; 2013년 10월 28일 채택 *Corresponding author

E-mail: chungtw@sejong.ac.kr

Address: Department of Energy \& Mineral Resources, Sejong University, Seoul 143-747, Korea

(C)2013, Korean Society of Earth and Exploration Geophysicists

This is an Open Access article distributed under the terms of the Creative Commons Attribution Non-Commercial License (http://creativecommons.org/ licenses/by-nc/3.0/) which permits unrestricted non-commercial use, distribution, and reproduction in any medium, provided the original work is properly cited. 'least square adjustment', is geodetic measurement and analysis. There were studies of both theory and application based on different approaches to derive principal strain from displacement data.

In this report, we summarize a direct and slightly different calculation procedure to attain the most probable and unbiased estimates of strain tensor, principal strain, and rotation for given triangular network measurement. Unlike conventional procedure, in which strain tensor and rotation angle are simultaneously determined (Hamdy 2004; Pietrantonio and Riguzzi, 2004), we use two step procedures - first calculate deformation tensor and then calculate other observables accordingly.

Often one may prefer smaller-spacing network to attain strain pattern in the given area for better resolution. However, we assure that the network triangle size must be taken properly with care. This is due to abrupt increase of uncer- 
tainty in those estimates with decrease of triangle size. Therefore proper size network should be chosen with error assessment. We applied our procedure to the co-seismic GPS displacement in South Korea due to the 2011 Tohoku-Oki Earthquake $(M=9.0)$ and attained the estimate of associated strain field and related.

\section{Gauss-Markov Observation Equation: Brief Review}

Method of observation equation for linear model is briefly summarized below. More description on the least square estimation technique is given in Appendix. There are standard materials about the Gauss-Markov observation equation (see for example, Schaffrin (1999), Uotila (1986), Mikhail and Ackermann (1976)). Write the linear model of observation and parameters as

$$
\left[\begin{array}{c}
y_{1} \\
y_{2} \\
\cdot \\
\cdot \\
\cdot \\
y_{n}
\end{array}\right]=\left[\begin{array}{cccccc}
a_{11} & a_{12} & \cdot & \cdot & \cdot & a_{1 m} \\
a_{21} & a_{22} & \cdot & \cdot & \cdot & a_{2 m} \\
\cdot & \cdot & \cdot & \cdot & \cdot & \cdot \\
\cdot & \cdot & \cdot & \cdot & \cdot & \cdot \\
\cdot & \cdot & \cdot & \cdot & \cdot & \cdot \\
a_{n 1} & a_{n 2} & \cdot & \cdot & \cdot & a_{n m}
\end{array}\right]\left[\begin{array}{c}
x_{1} \\
x_{2} \\
\cdot \\
\cdot \\
x_{m}
\end{array}\right]+\left[\begin{array}{c}
e_{1} \\
e_{2} \\
\cdot \\
\cdot \\
\cdot \\
e_{n}
\end{array}\right]
$$

where $y_{1}, y_{2}, y_{3}, \ldots y_{n}$ are observations with errors as $e_{1}, e_{2}, e_{3}$, $\ldots e_{n}$, and $x_{1}, x_{2}, \ldots x_{m}$ are the parameters to be determined ( $n$ $>m$ ). This model can be expressed as $y_{i}=\Sigma_{j} a_{i j} x_{j}+e_{i}$ or $Y=$ $A X+\varepsilon$. The variance-covariance matrix for observed quantities is denoted as

$$
\Sigma=\left[\begin{array}{cccccc}
\sigma_{1}^{2} & \sigma_{12} & \cdot & \cdot & \cdot & \sigma_{1 n} \\
\sigma_{21} & \sigma_{2}^{2} & \cdot & \cdot & \cdot & \sigma_{2 n} \\
\cdot & \cdot & \cdot & \cdot & \cdot & \cdot \\
\cdot & \cdot & \cdot & \cdot & \cdot & \cdot \\
\cdot & \cdot & \cdot & \cdot & \cdot & \cdot \\
\sigma_{n 1} & \sigma_{n 2} & \cdot & \cdot & \cdot & \sigma_{n}^{2}
\end{array}\right]
$$

where $\sigma_{i}^{2}=\operatorname{var}\left(y_{i}\right)$ and $\sigma_{i j}=\operatorname{cov}\left(y_{i}, y_{j}\right)$. Forward and inverse relations between $\Sigma_{y}$ and $\Sigma_{x}$ are given as $\Sigma_{y}=\mathrm{A} \Sigma_{x} A^{T}$ and $\Sigma_{x}=$ $\left(A^{T} A\right)^{-1} A^{T} \Sigma_{y} A\left(A^{T} A\right)^{-1}$. By minimizing the weighted sum of square error $S=\varepsilon^{T} \Sigma^{-1} \varepsilon$, the best unbiased estimate of $X$ is found as

$$
\hat{X}=\left(A^{T} \Sigma^{-1} A\right)^{-1}\left(A^{T} \Sigma^{-1} Y\right) .
$$

\section{Strain Estimation from Displacement of Triangular Array}

There have been various studies about both methodology and application of the strain estimation from displacement data (Pietrantonio and Riguzzi, 2004 and references cited therein, Hamdy, 2004). Both Pietrantonio \& Riguzzi (2004) and Hamdy (2004) expressed the strain tensor and rotation angle in one observation equation so that they would be determined simultaneously. However, we suggest another procedure, which is composed of two step calculations. Given the 2-dim displacement vector measurements at three stations (Fig. 1), we firstly acquire the most probable and unbiased estimate of strain tensor by using the least square technique, and then, estimate principal strain, rotation angle as following step. In Fig. 1, three 2-dim displacement vectors denoted as $\left(u_{i}, v_{i}\right)$ are represented as arrows, while the locations of three stations are denoted as $\left(x_{i}, y_{i}\right)$ for $i=1,2$ and 3. The center of the triangle is denoted as $\left(x_{c}, y_{c}\right)$, and the relative locations of each station with respect to the center are denoted as $\left(\Delta x_{i}, \Delta y_{i}\right)$.

Write the displacement field as $(u, v)$, then with neglecting the second and higher order terms we can express three sets of $\left(u_{i}, v_{i}\right)$ as follows (Love, 1927).

$$
u_{i}=\frac{\partial u}{\partial x} \Delta x_{i}+\frac{\partial u}{\partial y} \Delta y_{i} \text { and } v_{i}=\frac{\partial v}{\partial x} \Delta x_{i}+\frac{\partial v}{\partial y} \Delta y_{i}(i=1,2 \text { and } 3)
$$

We rewrite these relations as the observation equation as the following.

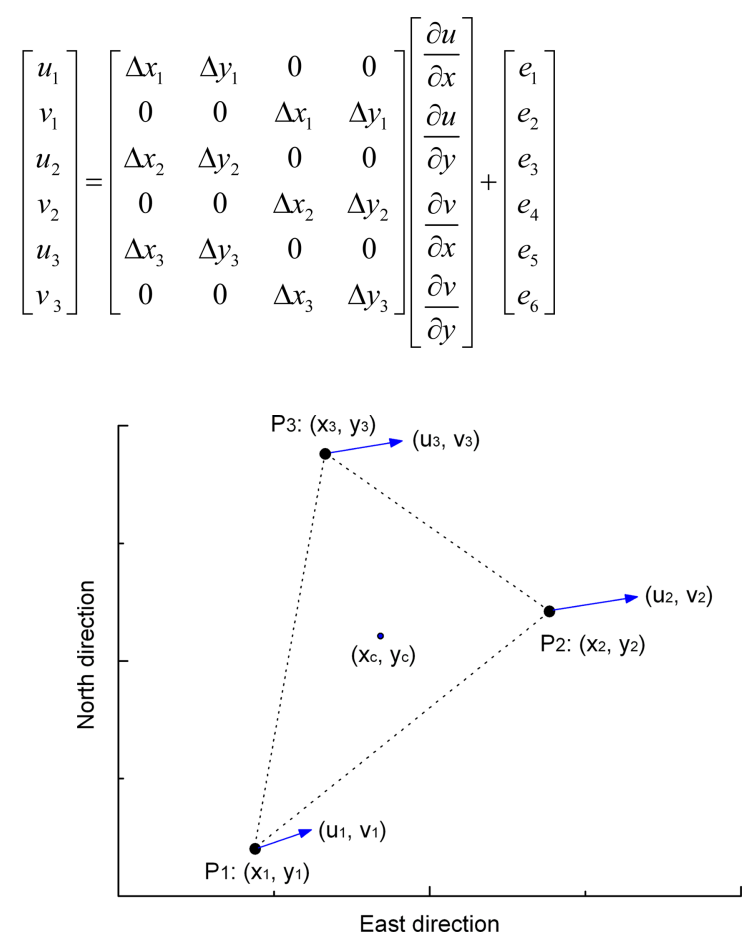

Fig. 1. Two dimensional displacement vectors measured at three stations. 
The most probable and unbiased estimate of the four parameters; $\partial u / \partial x, \partial u / \partial y, \partial v / \partial x$, and $\partial v / \partial y$ can readily be acquired as least square error solution. The four parameters compose deformation tensor. Given the variance-covariance $\Sigma_{y}$ for observation, the variance-covariance of these parameters $\Sigma_{x}$ can be acquired by using the relation; $\Sigma_{x}=\left(A^{T} A\right)^{-1} A^{T} \Sigma_{y} A\left(A^{T}\right.$ $A)^{-1}$, while Eq. (3) is expressed as $\hat{Y}=A \hat{X}$.

The strain tensor and principal strain are acquired accordingly, once the four deformation rates are known. The strain tensor $E_{i j}=1 / 2\left(\partial u_{i} / \partial x_{j}+\partial u_{j} / \partial x_{i}\right)$ can be written as

$$
\left[\begin{array}{ll}
E_{11} & E_{12} \\
E_{21} & E_{22}
\end{array}\right]=\left[\begin{array}{cc}
\frac{\partial u}{\partial x} & \frac{1}{2}\left(\frac{\partial u}{\partial y}+\frac{\partial v}{\partial x}\right) \\
\frac{1}{2}\left(\frac{\partial u}{\partial y}+\frac{\partial v}{\partial x}\right) & \frac{\partial v}{\partial y}
\end{array}\right]
$$

The deformation tensor $D_{i j}$ can be separated into symmetric part - strain tensor $E_{i j}$ and antisymmetric part - rotation tensor $O_{i j}$, i.e., $D_{i j}=E_{i j}+O_{i j}$, and matrix representation of this relation can be written as follows.

$$
\left[\begin{array}{ll}
\frac{\partial u}{\partial x} & \frac{\partial u}{\partial y} \\
\frac{\partial v}{\partial x} & \frac{\partial v}{\partial y}
\end{array}\right]=\left[\begin{array}{cc}
\frac{\partial u}{\partial x} & \frac{1}{2}\left(\frac{\partial u}{\partial y}+\frac{\partial v}{\partial x}\right) \\
\frac{1}{2}\left(\frac{\partial u}{\partial y}+\frac{\partial v}{\partial x}\right) & \frac{\partial v}{\partial y}
\end{array}\right]+\left[\begin{array}{cc}
0 & \frac{1}{2}\left(\frac{\partial u}{\partial y}-\frac{\partial v}{\partial x}\right) \\
\frac{1}{2}\left(\frac{\partial v}{\partial x}-\frac{\partial u}{\partial y}\right) & 0
\end{array}\right]
$$

The nonvanishing component of the rotation tensor; $O_{12}$ corresponds to the rotational angle in counterclockwise sense (small rotation of the whole region involved). Dilatation, which is the expansion rate, can be expressed as $\nabla \cdot \vec{u}=\frac{\partial u}{\partial x}+\frac{\partial v}{\partial y}$.

The definition of principal strain is that the strain is parallel to displacement along the principal direction, which can be written as

$$
\left[\begin{array}{ll}
E_{11} & E_{12} \\
E_{21} & E_{22}
\end{array}\right]\left[\begin{array}{l}
x \\
y
\end{array}\right]=\lambda\left[\begin{array}{l}
x \\
y
\end{array}\right]
$$

Both the direction and magnitude of the principal strain are acquired from this relation. First magnitude of principal strain $\lambda$ (often called eigenvalue) is found from the condition of nontrivial solution for $(x, y)$, which is

$$
\left|\begin{array}{cc}
E_{11}-\lambda & E_{12} \\
E_{21} & E_{22}-\lambda
\end{array}\right|=0
$$

or can be written as

$$
\lambda^{2}-\left(E_{11}+E_{22}\right) \lambda+E_{11} E_{22}-E_{12}^{2}=0
$$

Two values of the principal strain are acquired as

$$
\lambda=\frac{E_{11}+E_{22}}{2} \pm \frac{1}{2} \sqrt{\left(E_{11}-E_{22}\right)+4 E_{12}^{2}}
$$

Two perpendicular directions of principal strain can be found by inserting the value of $\lambda$ to Eq. (5) and then solving for ( $x$, $y$ ). The direction of principal strain can be stably identified as the eigenvector of Eq. (5) by using a FORTRAN built-in function 'ATAN2.' This direction may simply be acquired by a formula; $\theta=1 / 2 \tan ^{-1}\left(2 E_{12} / E_{11}-E_{22}\right)$, which is mathematically equivalent (Hamdy, 2004). The two step procedure of this study has been found to yield at least one more effective digits for observables. The robustness came from isolation of rotation angle from the first step of estimation and also from stability of direct estimation of rotation angle through considering sine and cosine of argument.

\section{Coseismic Deformation of South Korea due to the 2011 Tohoku-Oki Earthquake}

In March 11 of the year 2011, an extremely large and devastating earthquake occurred in Japan. Its magnitude was known to be 9.0, and therefore its energy roughly amounts to $2.0 \times 10^{18}$ joule or explosion of TNT 480 mega ton (Gutenberg and Richter, 1956). Coseismic displacements of a few meters were observed in Japan near the focus. In Fig. 2, the coseismic displacement of Korea measured by 73 GPS stations are illustrated (Baek, 2012), values of the two components and others are also given in Table 1 for convenient use in future. All the stations were found to have undergone Eastward displacement. Largest displacement of $5.38 \mathrm{~cm}$ was found at DOKD station, while smallest displacement of 1.05 $\mathrm{cm}$ was found at MARA station.

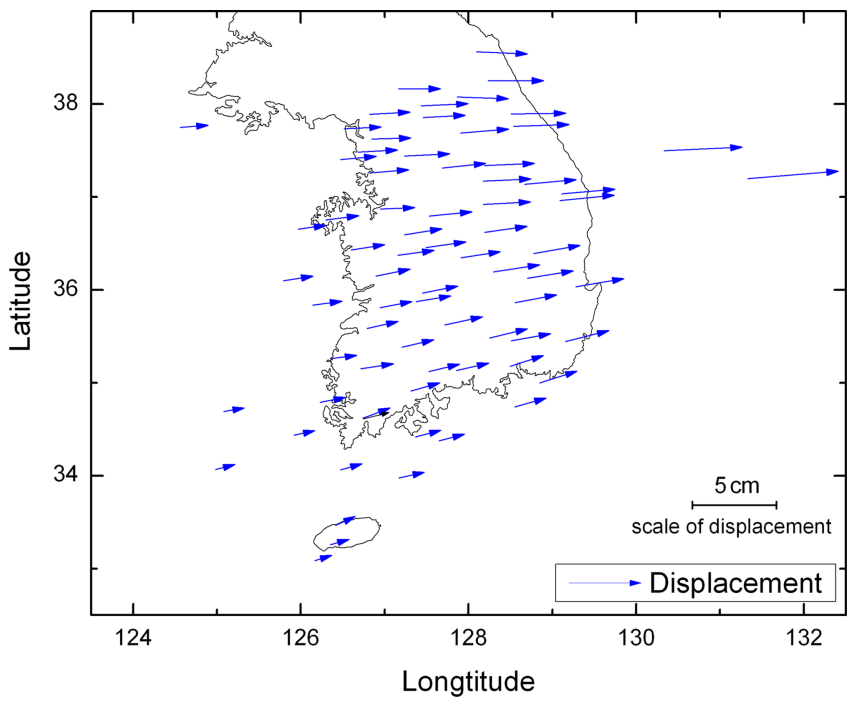

Fig. 2. GPS coseismic displacement of Korea due to the 2011 Tohoku earthquake. 
Table 1. GPS measurement data for the co-seismic displacement in Korea due to the 2011 Tohoku-Oki earthquake. Each longitude and latitude of GPS station given in [deg] of East and North, and two components of the displacement vector and their standard deviations given in [cm] (after Baek, 2012).

\begin{tabular}{|c|c|c|c|c|c|c|c|}
\hline \multicolumn{2}{|c|}{ Station } & \multirow{2}{*}{$\begin{array}{c}\text { Longitude } \\
128.976\end{array}$} & \multirow{2}{*}{$\begin{array}{r}\text { Latitude } \\
36.164\end{array}$} & \multirow{2}{*}{$\frac{U}{2.73}$} & \multirow{2}{*}{$\frac{\sigma(\mathrm{u})}{0.13}$} & \multirow{2}{*}{$\frac{\mathrm{V}}{0.41}$} & \multirow{2}{*}{$\frac{\sigma(\mathrm{v})}{0.16}$} \\
\hline 01 & BHAO & & & & & & \\
\hline 02 & DAEJ & 127.374 & 36.399 & 2.16 & 0.13 & 0.26 & 0.13 \\
\hline 03 & JEJU & 126.462 & 33.288 & 1.13 & 0.13 & 0.29 & 0.16 \\
\hline 04 & MKPO & 126.381 & 34.817 & 1.52 & 0.11 & 0.27 & 0.14 \\
\hline 05 & MLYN & 128.744 & 35.491 & 2.35 & 0.12 & 0.39 & 0.15 \\
\hline 06 & SBAO & 128.457 & 36.934 & 2.84 & 0.16 & 0.13 & 0.18 \\
\hline 07 & $\mathrm{SKCH}$ & 128.565 & 38.251 & 3.31 & 0.20 & -0.01 & 0.16 \\
\hline 08 & SKMA & 126.918 & 37.494 & 2.35 & 0.11 & 0.12 & 0.13 \\
\hline 09 & $\mathrm{KOHG}$ & 127.519 & 34.454 & 1.53 & 0.14 & 0.35 & 0.13 \\
\hline 10 & ANHN & 126.135 & 36.674 & 1.65 & 0.17 & 0.21 & 0.15 \\
\hline 11 & $\mathrm{CCHN}$ & 127.715 & 37.994 & 2.78 & 0.14 & 0.12 & 0.18 \\
\hline 12 & DANG & 126.603 & 34.098 & 1.28 & 0.18 & 0.32 & 0.16 \\
\hline 13 & DOKD & 131.870 & 37.239 & 5.37 & 0.11 & 0.39 & 0.13 \\
\hline 14 & $\mathrm{EOCH}$ & 125.968 & 36.125 & 1.77 & 0.16 & 0.24 & 0.14 \\
\hline 15 & GASA & 126.043 & 34.461 & 1.25 & 0.16 & 0.26 & 0.12 \\
\hline 16 & GEOM & 127.322 & 34.008 & 1.52 & 0.13 & 0.30 & 0.16 \\
\hline 17 & HGDO & 125.204 & 34.711 & 1.23 & 0.19 & 0.17 & 0.15 \\
\hline 18 & HOMI & 129.567 & 36.078 & 2.87 & 0.14 & 0.44 & 0.15 \\
\hline 19 & JEOJ & 128.399 & 38.552 & 3.03 & 0.17 & -0.13 & 0.17 \\
\hline 20 & JUKB & 129.429 & 37.058 & 3.19 & 0.17 & 0.25 & 0.15 \\
\hline 21 & JUMN & 128.834 & 37.898 & 3.27 & 0.15 & 0.03 & 0.14 \\
\hline 22 & MARA & 126.269 & 33.117 & 1.01 & 0.12 & 0.28 & 0.14 \\
\hline 23 & MLDO & 126.315 & 35.858 & 1.74 & 0.15 & 0.20 & 0.13 \\
\hline 24 & MOOJ & 127.583 & 35.903 & 2.07 & 0.14 & 0.31 & 0.14 \\
\hline 25 & PYCH & 128.488 & 37.350 & 3.01 & 0.19 & 0.11 & 0.17 \\
\hline 26 & SEOI & 128.738 & 34.788 & 1.86 & 0.15 & 0.48 & 0.15 \\
\hline 27 & $\mathrm{SOCH}$ & 124.729 & 37.760 & 1.66 & 0.12 & 0.11 & 0.14 \\
\hline 28 & SOHE & 125.099 & 34.095 & 1.14 & 0.17 & 0.27 & 0.16 \\
\hline 29 & SORI & 127.801 & 34.412 & 1.50 & 0.18 & 0.36 & 0.14 \\
\hline 30 & SUWN & 127.054 & 37.276 & 2.33 & 0.13 & 0.18 & 0.15 \\
\hline 31 & ULLE & 130.798 & 37.518 & 4.66 & 0.18 & 0.19 & 0.16 \\
\hline 32 & YNDO & 129.071 & 35.062 & 2.22 & 0.12 & 0.63 & 0.11 \\
\hline 33 & BOEN & 127.730 & 36.488 & 2.38 & 0.12 & 0.30 & 0.13 \\
\hline 34 & $\mathrm{CHCN}$ & 127.711 & 37.869 & 2.51 & 0.38 & 0.12 & 0.22 \\
\hline 35 & CHEN & 127.155 & 36.878 & 2.04 & 0.16 & 0.09 & 0.17 \\
\hline 36 & СНJU & 126.530 & 33.514 & 1.16 & 0.14 & 0.48 & 0.16 \\
\hline 37 & CHLW & 127.415 & 38.164 & 2.51 & 0.11 & 0.02 & 0.16 \\
\hline 38 & CHNG & 128.478 & 35.533 & 2.26 & 0.09 & 0.48 & 0.11 \\
\hline 39 & CHSG & 129.056 & 36.436 & 2.77 & 0.15 & 0.43 & 0.13 \\
\hline 40 & CHWN & 128.693 & 35.236 & 2.00 & 0.15 & 0.58 & 0.16 \\
\hline 41 & CHYG & 126.801 & 36.459 & 2.01 & 0.12 & 0.29 & 0.16 \\
\hline 42 & CNJU & 127.461 & 36.627 & 2.23 & 0.12 & 0.32 & 0.15 \\
\hline 43 & DOND & 127.061 & 37.902 & 2.41 & 0.11 & 0.11 & 0.14 \\
\hline 44 & $\mathrm{GOCH}$ & 127.943 & 35.668 & 2.24 & 0.17 & 0.44 & 0.17 \\
\hline 45 & GSAN & 127.787 & 36.816 & 2.55 & 0.12 & 0.22 & 0.16 \\
\hline 46 & HADG & 127.709 & 35.162 & 1.83 & 0.20 & 0.40 & 0.16 \\
\hline 47 & HONC & 128.194 & 37.709 & 2.87 & 0.15 & 0.21 & 0.13 \\
\hline 48 & $\mathrm{INCH}$ & 126.686 & 37.420 & 2.12 & 0.14 & 0.16 & 0.17 \\
\hline 49 & INJE & 128.171 & 38.069 & 3.05 & 0.22 & -0.09 & 0.31 \\
\hline 50 & JAHG & 126.900 & 34.675 & 1.61 & 0.14 & 0.55 & 0.17 \\
\hline 51 & JINJ & 128.050 & 35.173 & 1.94 & 0.10 & 0.41 & 0.13 \\
\hline
\end{tabular}

Table 1. Continued.

\begin{tabular}{lccccccc}
\hline \hline \multicolumn{2}{c}{ Station } & Longitude & Latitude & $\mathrm{U}$ & $\sigma(\mathrm{u})$ & $\mathrm{V}$ & $\sigma(\mathrm{v})$ \\
\hline 52 & JUNG & 126.974 & 35.623 & 1.85 & 0.14 & 0.39 & 0.12 \\
53 & JUNJ & 127.135 & 35.843 & 1.90 & 0.11 & 0.33 & 0.14 \\
54 & KANR & 128.868 & 37.771 & 3.31 & 0.16 & 0.10 & 0.15 \\
55 & KUNW & 128.574 & 36.233 & 2.77 & 0.19 & 0.37 & 0.15 \\
56 & KWNJ & 126.910 & 35.178 & 1.94 & 0.16 & 0.26 & 0.16 \\
57 & MUJU & 127.661 & 36.003 & 2.11 & 0.11 & 0.39 & 0.13 \\
58 & NAMW & 127.396 & 35.423 & 1.90 & 0.12 & 0.40 & 0.13 \\
59 & NONS & 127.099 & 36.186 & 2.04 & 0.11 & 0.37 & 0.14 \\
60 & PAJU & 126.738 & 37.746 & 2.22 & 0.11 & 0.09 & 0.13 \\
61 & SEOS & 126.494 & 36.776 & 1.97 & 0.10 & 0.23 & 0.11 \\
62 & SNJU & 128.144 & 36.379 & 2.35 & 0.14 & 0.33 & 0.14 \\
63 & SONC & 127.486 & 34.957 & 1.72 & 0.13 & 0.43 & 0.14 \\
64 & SOUL & 127.080 & 37.630 & 2.34 & 0.12 & 0.07 & 0.13 \\
65 & TABK & 128.976 & 37.161 & 3.09 & 0.29 & 0.24 & 0.18 \\
66 & TEGN & 128.802 & 35.906 & 2.48 & 0.14 & 0.42 & 0.14 \\
67 & WNJU & 127.947 & 37.337 & 2.60 & 0.11 & 0.23 & 0.12 \\
68 & WOLS & 129.416 & 35.504 & 2.58 & 0.14 & 0.58 & 0.14 \\
69 & WULJ & 129.413 & 36.992 & 3.24 & 0.13 & 0.29 & 0.12 \\
70 & YANP & 127.506 & 37.454 & 2.70 & 0.12 & 0.12 & 0.13 \\
71 & YECH & 128.446 & 36.651 & 2.52 & 0.12 & 0.33 & 0.14 \\
72 & YONK & 126.516 & 35.279 & 1.52 & 0.16 & 0.18 & 0.15 \\
73 & YOWL & 128.462 & 37.183 & 2.85 & 0.11 & 0.11 & 0.13 \\
\hline & & & & & & &
\end{tabular}

To see the most representative amount of principal strain, least square solution for the largest triangle was acquired; +64.42 and -6.25 nanostrain along the directions of 13.89 and -76.11 degrees with respect to the East (Fig. 3). The value of dilatation for this single largest triangle was found as $\Delta=E_{11}+E_{22}=58.2$ nanostrain. Therefore, South Korea, as a whole, was slightly elongated in roughly the East-West direction and was very slightly compressed in North-South

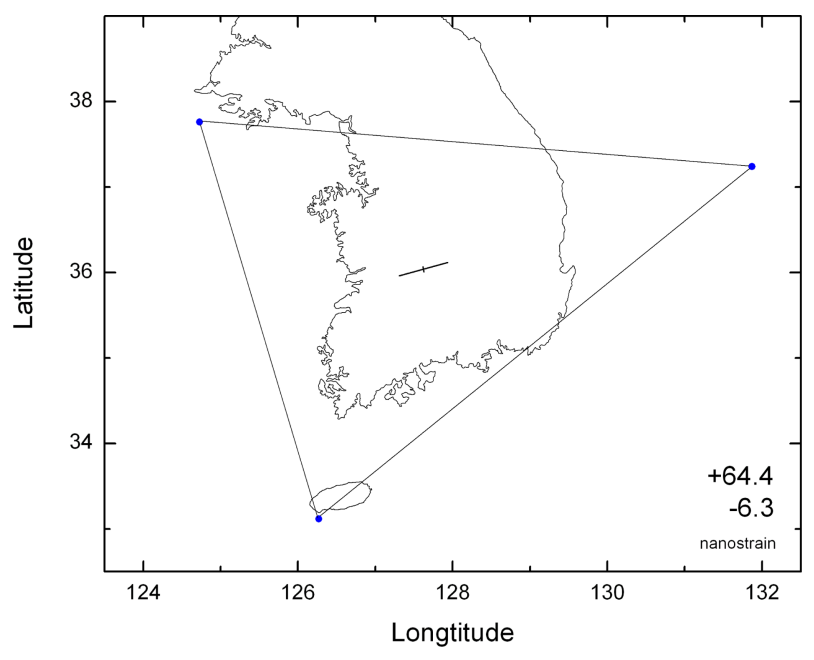

Fig. 3. Principal strain estimated for coseismic displacements due to the Tohoku earthquake at the largest triangular GPS station array in Korea. 
(a)

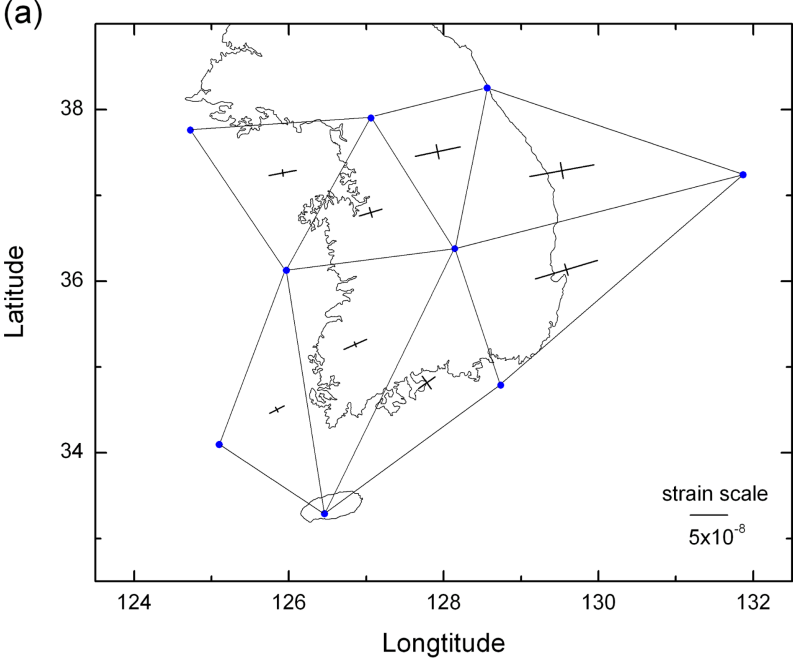

(b)

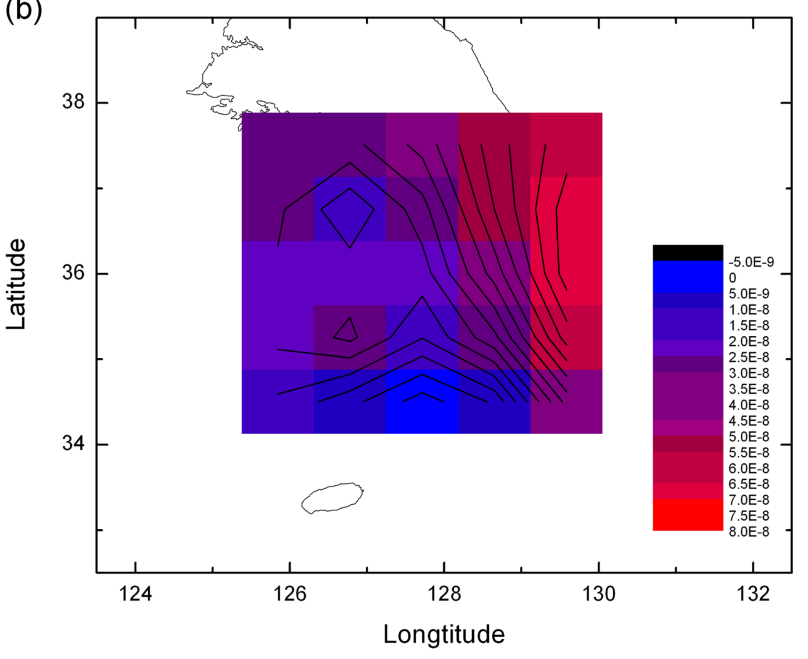

(c)

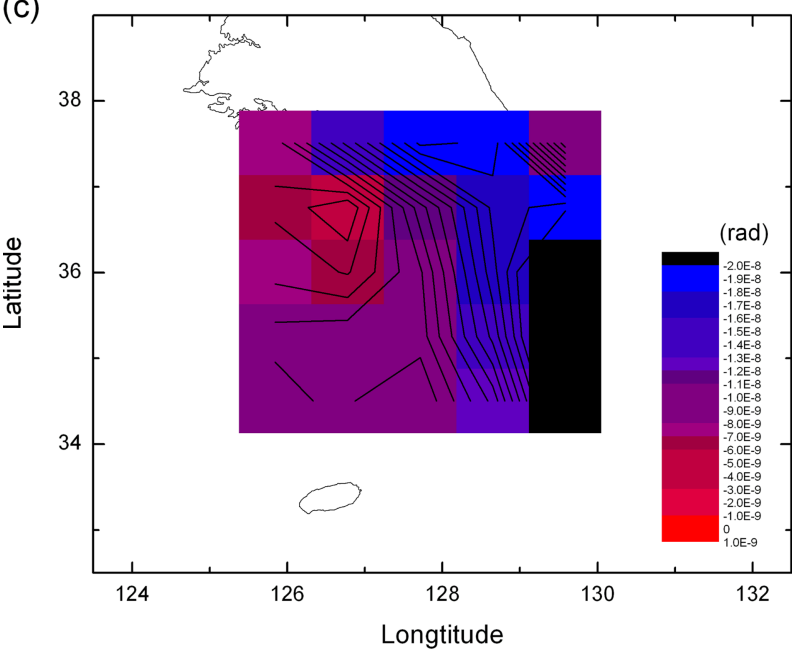

Fig. 4. Principal strain, dilatation, and rotation estimated for coseismic displacements due to the Tohoku earthquake at 8 large triangle GPS station network in Korea; (a) principal strain, (b) dilatation, and (c) rotation.

direction due to the earthquake. The value of rotation was found as $O=-1.23 \times 10^{-8}(\mathrm{rad})$, so that South Korea was slightly rotated in clockwise direction.

The principal strain, dilatation, and rotation for 8 triangle network were estimated accordingly and are illustrated (Fig. 4). Their values are given in Table 2(b). A little detail of estimates for this network is given as the following. Since the epicenter of the earthquake is located at far East from Korea, not only the displacement but also the strain was large in the Eastern part of Korea. Both the displacement and strain varied almost inversely proportional to the distance from the epicenter. The value of elongation principal strain $E_{11}$ was largest at the Northeastern region and smallest at the Southwestern region, and varied from 84.7 to 21.4 nanostrain (from East to West). Likewise, the value of compression principal strain $E_{22}$ was largest at the Northeastern region and smallest at the Southwestern region, and varied from -21.1 to -7.1 nanostrain (from East to West). Rotation angles estimated for each triangular arrays were all small and counterclockwise, and varied from $2.33 \times 10^{-9}$ to $6.52 \times 10^{-10}$ (unit: radian). Rotation was largest at the East lower region and smallest at Kyunggi-Choongnam region.

As the size of each triangular array become smaller, the acquired principal strain better show localized pattern in the whole principal strain. The finer the network becomes, the more details of the localized pattern could be known. However, care should be taken in choosing the triangular network size and configuration, because calculation instability also grows larger for smaller network. To see this, we go back to the observation equation (Eq. 3). The elements of $A$ matrix of Eq. (3) (in the form of $Y=A X+\varepsilon$ ) are $\Delta x_{i}$ and $\Delta y_{i}$, which are proportional to the size of each triangular array in the network. Evidently the variance-covariance matrix of deformation tensor estimate will become larger for smaller network, according to the law of error propagation. One may expect the variance be inversely proportional to the square of the dimension, i.e., to the area.

The variance-covariance matrix of the deformation tensor $\Sigma_{x}=\left(A^{T} A\right)^{-1} A^{T} \Sigma_{y} A\left(A^{T} A\right)^{-1}$ were calculated for the three cases of 1,8 and 59 triangle networks, and their r.m.s values were found as $0.077,0.91$ and 18 nanostrain respectively. Therefore the least square solution for the 59 triangle network is prone to contain large amount of error (same order of strain estimate itself), while the estimate for 1 or 8 triangle network is either quite stable or acceptable. In Table 2(a) (c), r.m.s. values of error in the estimate of deformation tensor for each triangles are given together with principal strain, dilatation and rotation for the three kinds of triangular net- 
Table 2. (a)-(c) Triangular network configurations and the estimates of principal strain, dilatation, rotation, and standard deviation of deformation tensor (a-c: three kinds networks of 1, 8, and 59 triangles each). Principal strain, dilatation, standard deviation are dimensionless and given in nanoscale. Negative values of strain refer to compression. Principal direction is denoted by counterclockwise angle from the East (in parenthesis). The value of rotation is given as counterclockwise angle in radian. Only some parts of content are shown for Table 2(c).

(a) Estimated Parameters (1 triangle)

\begin{tabular}{ccccccc}
\hline \hline triangle & stations & 2 principal strain $($ angle) & dilatation & rotation & s.t.d. \\
\hline 1 & $27-22-13$ & $64.4\left(13.9^{\circ}\right)$ & $-6.3\left(-76.1^{\circ}\right)$ & 58.1 & $-1.23 \mathrm{E}-8$ & 0.077 \\
\hline
\end{tabular}

(b) Estimated Parameters (8 triangles)

\begin{tabular}{cclcccc}
\hline \hline triangle & stations & \multicolumn{2}{c}{2 principal strain $($ angle $)$} & dilatation & rotation & s.t.d. \\
\hline 1 & $27-14-43$ & $36.0\left(10.4^{\circ}\right)$ & $-8.3\left(-79.6^{\circ}\right)$ & 27.7 & $-7.32 \mathrm{E}-9$ & 0.61 \\
2 & $14-62-43$ & $30.8\left(17.2^{\circ}\right)$ & $-1.3\left(-72.8^{\circ}\right)$ & 17.3 & $-6.52 \mathrm{E}-9$ & 0.72 \\
3 & $43-62-07$ & $59.5\left(11.8^{\circ}\right)$ & $-1.9\left(-78.2^{\circ}\right)$ & 40.7 & $-2.01 \mathrm{E}-8$ & 1.00 \\
4 & $07-62-13$ & $84.7\left(10.6^{\circ}\right)$ & $-2.1\left(-79.4^{\circ}\right)$ & 63.6 & $-1.23 \mathrm{E}-8$ & 0.52 \\
5 & $14-28-03$ & $21.4\left(26.7^{\circ}\right)$ & $-7.3\left(-63.3^{\circ}\right)$ & 14.1 & $-1.10 \mathrm{E}-8$ & 1.55 \\
6 & $14-03-62$ & $32.4\left(23.3^{\circ}\right)$ & $-7.1\left(-66.7^{\circ}\right)$ & 25.3 & $-9.62 \mathrm{E}-9$ & 0.61 \\
7 & $03-26-62$ & $26.2\left(35.5^{\circ}\right)$ & $-2.0\left(-54.5^{\circ}\right)$ & 6.0 & $-8.94 \mathrm{E}-9$ & 1.09 \\
8 & $62-26-13$ & $83.8\left(16.6^{\circ}\right)$ & $-1.5\left(-73.4^{\circ}\right)$ & 68.4 & $-2.33 \mathrm{E}-8$ & 0.66 \\
\hline
\end{tabular}

(c) Estimated Parameters (59 triangles)

\begin{tabular}{|c|c|c|c|c|c|c|}
\hline \multirow{2}{*}{$\begin{array}{c}\text { triangle } \\
1\end{array}$} & \multirow{2}{*}{$\begin{array}{c}\text { stations } \\
19-49-07\end{array}$} & \multicolumn{2}{|c|}{2 principal strain (angle) } & \multirow{2}{*}{$\begin{array}{c}\text { dilatation } \\
76.0\end{array}$} & \multirow{2}{*}{$\begin{array}{l}\text { rotation } \\
3.74 \mathrm{E}-8\end{array}$} & \multirow{2}{*}{$\begin{array}{c}\text { s.t.d. } \\
34.3\end{array}$} \\
\hline & & $96.6\left(178.5^{\circ}\right)$ & $-20.6\left(-91.5^{\circ}\right)$ & & & \\
\hline 2 & $37-49-12$ & $81.6\left(179.1^{\circ}\right)$ & $-3.9\left(-90.9^{\circ}\right)$ & 77.7 & $-1.54 \mathrm{E}-8$ & 5.4 \\
\hline 3 & $37-34-49$ & $95.1\left(9.7^{\circ}\right)$ & $-54.2\left(-80.3^{\circ}\right)$ & 40.9 & $-4.88 \mathrm{E}-8$ & 27.0 \\
\hline 4 & $37-43-34$ & $19.1\left(8.2^{\circ}\right)$ & $-31.7\left(-81.8^{\circ}\right)$ & -12.6 & $-7.42 \mathrm{E}-9$ & 17.1 \\
\hline 5 & $43-30-34$ & $19.1\left(12.0^{\circ}\right)$ & $-11.4\left(-78.0^{\circ}\right)$ & 7.7 & $-5.13 \mathrm{E}-9$ & 7.0 \\
\hline 6 & $43-60-30$ & $60.9\left(9.6^{\circ}\right)$ & $-12.2\left(-80.4^{\circ}\right)$ & 48.7 & $9.98 \mathrm{E}-10$ & 15.9 \\
\hline 7 & $34-30-67$ & $34.0\left(2.6^{\circ}\right)$ & $-16.0\left(-87.4^{\circ}\right)$ & 18.0 & $5.31 \mathrm{E}-9$ & 9.3 \\
\hline 8 & $34-67-47$ & $92.3\left(8.7^{\circ}\right)$ & $-15.6\left(-81.3^{\circ}\right)$ & 76.7 & $-8.33 \mathrm{E}-10$ & 24.5 \\
\hline 9 & $34-47-49$ & $105.7\left(6.3^{\circ}\right)$ & $-77.7\left(-83.7^{\circ}\right)$ & 28.0 & $-3.03 \mathrm{E}-8$ & 23.3 \\
\hline 10 & $60-61-30$ & $60.1\left(6.5^{\circ}\right)$ & $-15.1\left(-83.5^{\circ}\right)$ & 45.0 & $-2.73 \mathrm{E}-9$ & 7.9 \\
\hline 11 & $49-21-07$ & $65.3\left(26.4^{\circ}\right)$ & $-12.6\left(-63.6^{\circ}\right)$ & 52.7 & $-9.99 \mathrm{E}-9$ & 28.6 \\
\hline 12 & $49-47-21$ & $55.7\left(9.5^{\circ}\right)$ & $-78.8\left(-80.5^{\circ}\right)$ & -23.1 & $-2.57 \mathrm{E}-8$ & 21.8 \\
\hline 13 & $47-25-21$ & $68.4\left(169.7^{\circ}\right)$ & $1.3\left(-100.3^{\circ}\right)$ & 69.7 & $-2.07 \mathrm{E}-8$ & 11.5 \\
\hline 14 & $47-67-25$ & $83.7\left(178.3^{\circ}\right)$ & $8.5\left(-91.7^{\circ}\right)$ & 92.2 & $-2.26 \mathrm{E}-8$ & 11.2 \\
\hline 15 & $21-25-65$ & $39.4\left(20.1^{\circ}\right)$ & $-31.1\left(-69.9^{\circ}\right)$ & 8.4 & $-4.03 \mathrm{E}-9$ & 12.3 \\
\hline- & - & - & - & - & - & - \\
\hline- & - & - & - & - & - & - \\
\hline- & - & - & - & - & - & - \\
\hline 57 & $10-05-68$ & $61.5\left(46.9^{\circ}\right)$ & $16.9\left(-43.1^{\circ}\right)$ & 78.4 & $-8.19 \mathrm{E}-9$ & 27.5 \\
\hline 58 & $05-32-68$ & $56.3\left(25.3^{\circ}\right)$ & $-49.9\left(-64.7^{\circ}\right)$ & 6.4 & $-8.91 \mathrm{E}-9$ & 7.6 \\
\hline 59 & $05-26-32$ & $93.6\left(30.5^{\circ}\right)$ & $-48.7\left(-59.5^{\circ}\right)$ & 44.9 & $-3.52 \mathrm{E}-11$ & 16.9 \\
\hline
\end{tabular}

works.

In Fig. 5(a) $\sim(\mathrm{c})$, the principal strain, dilatation, and rotation estimated for the 59 triangular networks are illustrated. The value of principal strain varies more or less in the same range, however, the principal direction show large fluctuation at regions. This complicated feature possibly reflects locally different direction of principal strain, but also possibly was misled by erroneous estimation due to too small size of each network triangles. Likewise estimated dilatation and rotation show various features over the all part of the Korean peninsula, but not all of these features can be taken as real. We found the same type erroneous estimation (worse than ours 
(a)

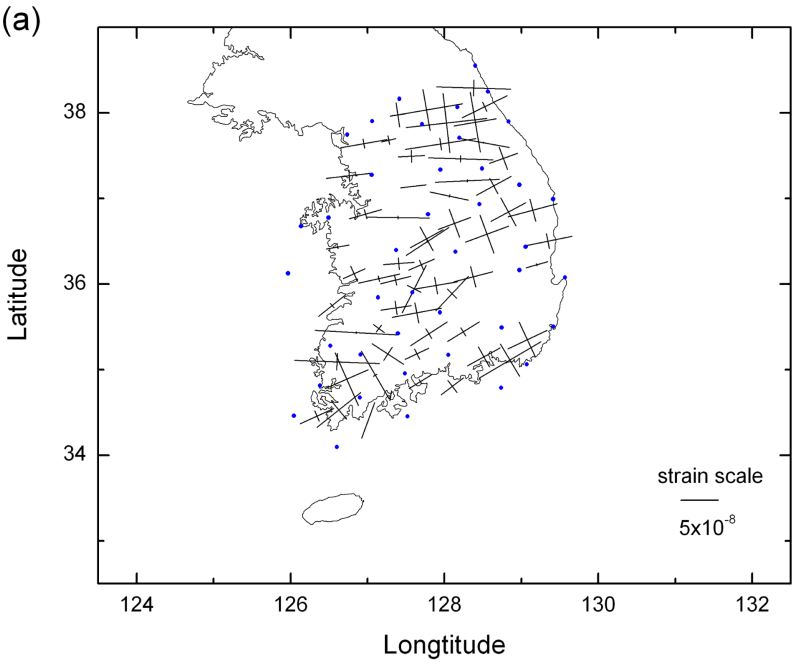

(b)

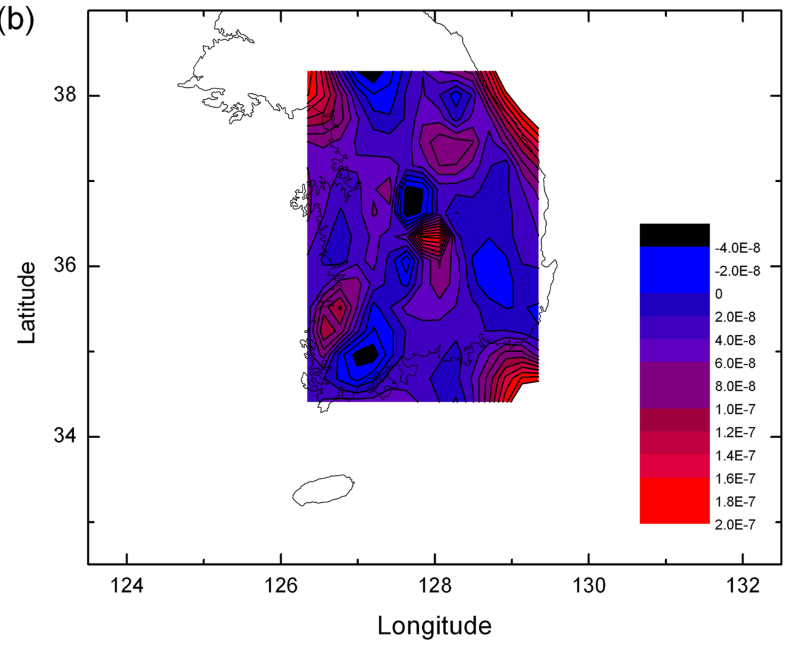

(c)

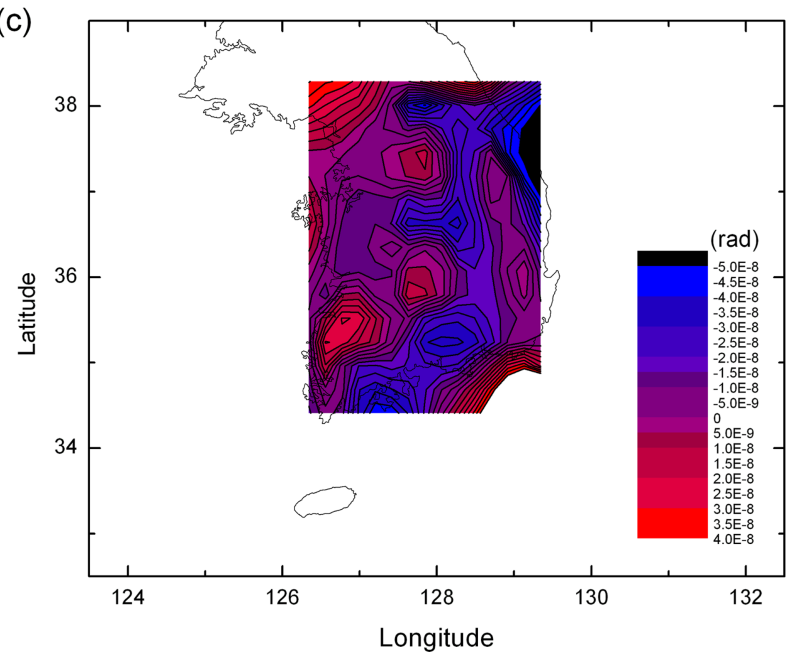

for the 59 triangular networks) in a pre-published report, and such has been one of our motives to write this article.

\section{Acknowledgments}

This study was supported by the fund of CATER 20128010 provided by Center for Atmospheric Sciences and Earthquake Research (CATER) of Korea. The authors thank Dr. Baek, J. to retrieve the co-seismic GPS displacement vector at 73 stations of Korea due to the Tohoku earthquake. The original GPS dataset had been supported by National Geographic Information Institute of Korea and Korea Astronomy and Space Science Institute. Directions and suggestions from two anonymous referees led valuable improvements of this article.

\section{References}

Baek, J., 2012, Geodetic Analysis on Crustal Deformation of the Korean Peninsula using GPS Observation, $\mathrm{PhD}$ dissertation, University of Science and Technology.

Gutenberg, B., and Richter, C. F., 1956, Earthquake Magnitude, Intensity, Energy, and Acceleration, Bulletin of Seismological Society of America, 46, 105-145.

Hamdy, E. A. 2004, Section of Strain Analysis from Network Deformation Data in Korean National GPS Network Report 2004.

Love, A. E. H., 1927, A Treatise on the Mathematical Theory of Elasticity, $4^{\text {th }}$ edition, Dover Publications, New York.

Mikhail, E. M., and Ackermann, F., 1976, Observations and Least Squares, IEP-A Dun-Donnelley Publisher, New York.

Pietrantonio, G., and Riguzzi, F., 2004, Three-dimensional strain tensor estimation by GPS observations: methodological aspects and geophysical applications, Journal of Geodynamics, 38, 118.

Schaffrin, B., 1999, Softly unbiased estimation, Part 1: The Gauss-Markov model, Linear Algebra and its Application, 289, 285-296.

Uotila, U. A., 1986, Notes on Adjustment Computations Part 1, Dep. of Geodetic Sc. \& Surveying, Ohio State University, Columbus, Ohio.

Fig. 5. Principal strain, dilatation, and rotation estimated for coseismic displacements due to the Tohoku earthquake at 59 triangle GPS station network in Korea; (a) principal strain, (b) dilatation, and (c) rotation. 


\section{Appendix: \\ Least Square Estimation: More Description}

(This appendix is included by the first author wishing it be helpful as tutorial. Basic discipline is its content in statistics, geodesy, and surveying, but not in most other branches of science and technology.)

Prior to describe the general least square error estimation with Gauss-Markov model, two simple examples for least square error estimation are considered. The first one is 'simple arithmetic mean'. Suppose we are to measure the weight of a coin using a scale. In case we make just one measurement and acquire $m_{1}$ as a result, then it would be the value we can take. If we measure twice and acquire $m_{1}$ and $m_{2}$, then normally we choose the value as $m_{0}=\left(m_{1}+m_{2}\right) / 2$, which is simple arithmetic mean. If we write the each differences of the two measurements from the mean value $m$ as $e_{1}=m_{1}-m$ and $e_{2}=m_{2}-m$. Write the sum of the squares of two errors as $S=e_{1}^{2}+e_{2}^{2}$, we find the sum $S$ becomes minimum for $m=\left(m_{1}+m_{2}\right) / 2=m_{0}$. Extension to multiple measurements is obvious, and we similarly find the corresponding arithmetic mean $m=\left(m_{1}+m_{2}+m_{3}+\cdots+m_{n}\right) / n$ as least square error estimate of the coin's weight.

As second example, consider a set of two dimensional data; $\left(x_{1}, y_{1}\right),\left(x_{2}, y_{1}\right),\left(x_{3}, y_{3}\right), \cdots,\left(x_{n}, y_{n}\right)$. Assuming an elongated distribution of the data in $x-y$ plane, we seek a line; $y=a x+b$, which somehow well fits the distributed data on the plane (Fig. 2). Write the difference between each data point and the fit line in $y$-direction as $e_{i}$; that is

$$
e_{i}=y_{i}-\left(a x_{i}+b\right) \text {. }
$$

Then we can define the sum of square error as

$$
S=e_{1}^{2}+e_{2}^{2}+e_{3}^{2}+\ldots+e_{n}^{2}=\sum_{i} e_{i}^{2}=\sum_{i}\left(y_{i}-a x_{i}-b\right)^{2} .
$$

To determine the two coefficients $a$ and $b$, we impose conditions as $\partial S / \partial a=0$ and $\partial S / \partial b=0$, which are written as follows.

$$
\begin{aligned}
& \frac{\partial}{\partial a} \sum_{i}\left(y_{i}-a x_{i}-b\right)^{2}=-2 \sum_{i} x_{i}\left(y_{i}-a x_{i}-b\right)=0, \\
& \frac{\partial}{\partial b} \sum_{i}\left(y_{i}-a x_{i}-b\right)^{2}=-2 \sum_{i}\left(y_{i}-a x_{i}-b\right)=0 .
\end{aligned}
$$

After rearranging terms, we can rewrite the two conditions in matrix form as

$$
\left[\begin{array}{cc}
\sum_{i} x_{i}^{2} & \sum_{i} x_{i} \\
\sum_{i} x_{i} & n
\end{array}\right]\left[\begin{array}{l}
a \\
b
\end{array}\right]=\left[\begin{array}{l}
\sum_{i} x_{i} y_{i} \\
\sum_{i} y_{i}
\end{array}\right] .
$$

Invert this relation and then we find values of $a$ and $b$ of desired fit line.

Method of observation equation for linear model can be summarized as below. Suppose we have redundancy in observation, i.e., more observations than parameters to be determined. Write the linear model as

$$
\left[\begin{array}{c}
y_{1} \\
y_{2} \\
\cdot \\
\cdot \\
\cdot \\
y_{n}
\end{array}\right]=\left[\begin{array}{cccccc}
a_{11} & a_{12} & \cdot & \cdot & \cdot & a_{1 m} \\
a_{21} & a_{22} & \cdot & \cdot & \cdot & a_{2 m} \\
\cdot & \cdot & \cdot & \cdot & \cdot & \cdot \\
\cdot & \cdot & \cdot & \cdot & \cdot & \cdot \\
\cdot & \cdot & \cdot & \cdot & \cdot & \cdot \\
a_{n 1} & a_{n 2} & \cdot & \cdot & \cdot & a_{n m}
\end{array}\right]\left[\begin{array}{c}
x_{1} \\
x_{2} \\
\cdot \\
\cdot \\
x_{m}
\end{array}\right]+\left[\begin{array}{c}
e_{1} \\
e_{2} \\
\cdot \\
\cdot \\
\cdot \\
e_{n}
\end{array}\right]
$$

where $y_{1}, y_{2}, y_{3}, \cdots y_{n}$ are observations with each errors as $e_{1}$, $e_{2}, e_{3}, \cdots e_{n}$, and $x_{1}, x_{2}, \cdots x_{m}$ are the parameters to be determined $(n>m)$. This relation can be equivalently rewritten as $y_{i}=\sum a_{i j} x_{j}+e_{i}$ or $Y=A X+\varepsilon$. Since the errors are random ones, then their expectation values are zeroes, and then we have $\hat{Y}=A \hat{X}$, where the hats denote expectation values. We may proceed to minimize sum of the squares of errors, however we would introduce concept of proper weight to observations in the minimizing condition. The variancecovariance matrix for observed quantities is denoted as

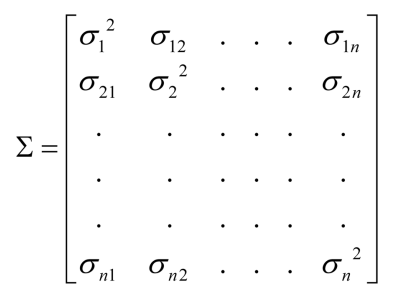

where $\sigma_{i}^{2}=\operatorname{var}\left(y_{i}\right)$ and $\sigma_{i j}=\operatorname{cov}\left(y_{i}, y_{i}\right)$. The law of error propagation is stated as; $\Sigma_{y}=A \Sigma_{x} A^{T}$ when two column vectors $X$ and $Y$ are related by $Y=A X$. To calculate $\Sigma_{y}$ from $\Sigma_{x}$ can be readily done using their relation; $\Sigma_{y}=\mathrm{A} \Sigma_{x} A^{T}$. To do the reverse we can equate as follows; $\Sigma_{x}=\left(A^{T} A\right)^{-1} A^{T} \Sigma_{y} A\left(A^{T} A\right)^{-1}$.

Write the weighted sum of square errors as $S=\varepsilon^{T} \Sigma^{-1} \varepsilon$. As the next step, we minimize $S$ and identify $\hat{X}$ as the corresponding values of parameters of $X$. The sum $S=\varepsilon^{T} \Sigma^{-1} \varepsilon$ can be explicitly shown as

$$
\begin{aligned}
S & =(Y-A X)^{T} \Sigma^{-1}(Y-A X) \\
& =Y^{T} \Sigma^{-1} Y-Y^{T} \Sigma^{-1} A X-X^{T} A^{T} \Sigma^{-1} Y+X^{T} A^{T} \Sigma^{-1} A X \\
& =Y^{T} \Sigma^{-1} Y-2 Y^{T} \Sigma^{-1} A X+X^{T} A^{T} \Sigma^{-1} A X
\end{aligned}
$$

where the last step comes due to $Y^{T} \Sigma^{-1} A X$ is just a number, and so $X^{T} A^{T} \Sigma^{-1} Y=Y^{T} \Sigma^{-1} A X$.

Take the partial derivative of the sum $S$ with respect to the parameters $X$, then claim it to vanish for $\hat{X}$ as follows. 


$$
\begin{gathered}
\frac{\partial S}{\partial X}=2 A^{T} \Sigma^{-1} A X-2 A^{T} \Sigma^{-1} Y \Rightarrow 0 \quad \text { for } \quad X=\hat{X} \\
A^{T} \Sigma^{-1} A \hat{X}-A^{T} \Sigma^{-1} Y=0
\end{gathered}
$$

i.e. $\hat{X}=\left(A^{T} \Sigma^{-1} A\right)^{-1}\left(A^{T} \Sigma^{-1} Y\right)$. For those, who are not familiar with matrix manipulation, alternative notation showing indexes explicitly is recommended $\left(e_{i}=y_{i}-\sum_{j} a_{i j} x_{j}, S=\sum_{i} \sum_{j} e_{i} \sigma_{i j} e_{j}\right.$, equate $\partial S / \partial x_{k}$ and then claim it to be zero).

We can deduce the same result as above for the two examples by using Gauss-Markov formulation. Suppose the weight of a coin is determined by the n-times repeated measurements. Then observation equation can be written as

$$
\left[\begin{array}{c}
m_{1} \\
m_{2} \\
\cdot \\
\cdot \\
\cdot \\
m_{n}
\end{array}\right]=\left[\begin{array}{c}
1 \\
1 \\
\cdot \\
\cdot \\
1
\end{array}\right] m+\left[\begin{array}{c}
e_{1} \\
e_{2} \\
\cdot \\
\cdot \\
\cdot \\
e_{n}
\end{array}\right]
$$

The least square estimate of the weight is given as $\hat{m}=$ $\left(A^{T} \Sigma^{-1} A\right)^{-1}\left(A^{T} \Sigma^{-1} Y\right)$. The simple arithmetic mean is readily found as $\hat{m}=\left(m_{1}+m_{2}+\cdots+m_{n}\right) / n$ by assuming equal and uncorrelated measurements. Likewise, linear regression of two dimensional data can be done by using observation equation as follows. To draw a line $(y=a x+b)$ for a given set of two dimensional data; $\left(x_{1}, y_{1}\right),\left(x_{2}, y_{2}\right),\left(x_{3}, y_{3}\right), \cdots,\left(x_{\mathrm{n}}\right.$, $\left.y_{\mathrm{n}}\right)$, we can write observation equation as

$$
\left[\begin{array}{c}
y_{1} \\
y_{2} \\
\cdot \\
\cdot \\
\cdot \\
y_{n}
\end{array}\right]=\left[\begin{array}{cc}
x_{1} & 1 \\
x_{2} & 1 \\
\cdot & \cdot \\
\cdot & \cdot \\
\cdot & \cdot \\
x_{n} & 1
\end{array}\right]\left[\begin{array}{l}
a \\
b
\end{array}\right]+\left[\begin{array}{c}
e_{1} \\
e_{2} \\
\cdot \\
\cdot \\
e_{n}
\end{array}\right]
$$

Then estimate of $\left[\begin{array}{l}\hat{a} \\ \hat{b}\end{array}\right]$ as $\left(A^{T} \Sigma^{-1} A\right)^{-1}\left(A^{T} \Sigma^{-1} Y\right)$ by assuming equal and uncorrelated data leads to the same result. 